\title{
Successful transition to retirement in Australia
}

\author{
Peter Forster* \\ University of Worcester, Worcester, United Kingdom \\ Mary Morris \\ Charles Darwin University, Darwin, Northern Territory, Australia
}

The transitions of old age include many changes in appearance, hormonal changes such as the menopause, changes in family structures such as children leaving home, and changes in work patterns such as retirement. The study of such transitions has grown rapidly in recent years. In the 1970s there were 203 peer-reviewed articles containing the keyword retirement, according to PsycINFO. By the 2000s this had risen to 1,804 (Shultz \& Wang, 2011).

Conceptualising retirement, Ekerdt noted, "The designation of retirement status is famously ambiguous because there are multiple overlapping criteria by which someone might be called retired, including career cessation, reduced work effort, pension receipt, or self-report" (p. 70) (Ekerdt, 2010). This study measures retirement via selfreport. Although Australians no longer face a compulsory retirement age, at which they are no longer considered useful to the workforce, retirement is still an important transition for individuals, their families, and for the wider society.

Based on estimates from the 2006 census and the 2007 Survey of Employment Arrangements, Retirement and Superannuation - the most recent for which such data are available - an estimated 7.7 million Australians were aged 45 years or over. Of these, 3.1 million people were retired (Australian Bureau of Statistics, 2009). As is evident, the likelihood of being retired increases with age. In 2007, there were more retired women (1.8 million) than retired men (1.3 million). The average age at retirement for women is 47, compared with 58 for men. For all age groups over 45 years, more men than women intend never to retire $(16.7 \%$ and $11.9 \%$ respectively) (Australian Bureau of Statistics, 2009).

Of those retirees who had worked in the last 20 years, the most common main reason for retiring is the retiree's health. This is a more common reason for retired men (38\%) than retired women (25\%). Other common reasons for retirement for men include financial reasons (20\%) and being retrenched or made redundant (10\%). While financial considerations are more likely to influence men, women are more likely to make their decision based on family considerations. Common reasons for women to retire include caring responsibilities (15\%) and to spend more time with their family or partner (13\%) (Australian Bureau of Statistics, 2009).

It is relatively easy to find advice about financial preparation for retirement, compared to successfully navigating the cognitive, emotional, or social aspects of the transition. What does retirement mean to those approaching it? Stokes found that it means the end of work and the loss of identity in response to a society that has a negative perception of old age (Stokes, 1992). This is consistent with the disengagement theory of aging in which aging is seen as a process of disengagement from other people (Cumming et al, 1961). On the other hand, the street protests seen in France in October 2010, in response to the French government's proposal to raise the retirement age from 60 to 62 , could be interpreted as some people looking forward to retirement as a release from the burden of employment.

In a study examining retirement experiences, three main groups of people who could be delineated on the basis of their experience were identified (Kloep \& Hendry, 2006).

*Email: p.forster@worc.ac.uk, mary.morris@cdu.edu.au

ISSN 2049-6869

http://dx.doi.org/10.7563/SSD_01_01_01 


\section{P. Forster \& M. Morris}

1. High distress - a small group who report one or more of a range of debilitating experiences such as major health problems, the loss of a partner, or other family tragedy. People in this group do not like their work and they do not adjust well to retirement. Their problems do not come from retirement per se, but from negative life experiences

2. Work as a lifestyle - a group whose interests and social networks are linked to work, and who are reluctant to give these up for retirement. People in this group experience adjustment problems from their perceived loss of social status

3. Life beyond work - a group who had enjoyed their jobs but who retired willingly, and often earlier than necessary, to have time to enjoy other activities. People in this group usually adapt well to retirement and lead active, well-structured lives

An aim of the present study is to identify which factors help people become part of this third group of successful retirees. One such factor seems to be social participation. This construct has been found to be related to the perceived quality of life of retirees (Bowling et al, 2004). In fact, a person's social participation has been implicated in depression, as studies have found that people who have experienced negative life events are less likely to experience depression if they have access to supportive relationships (Brown \& Harris, 1978; Monroe et al, 1983). Erikson considered old age as the stage of life in which we must resolve the crisis of integrity versus despair (Erikson, 1959). Those who achieve ego-integrity have a feeling that life's goals have been attained and that one's life experiences have been achieved without regret. According to this theory, living in a society which values youth and those in employment makes it more likely that older people will feel despair at the loss of health, meaning, and respect from others. Consistent with this idea is the finding that, once retired, many people are bored and lose a sense of meaning in life (Ebersole et al, 2007). Under these circumstances, it is perhaps not surprising that risk of depression is higher in old people relative to younger people. It may also be a contributing factor behind the increased risk of suicide amongst older men (De Leo et al, 2001).

Continuity theory predicts that retirement will be stressful for many people because of the discontinuity in a central and important role and suggests that there will be an overall decline in well-being after retirement. In this theoretical model, if people are to make a successful transition to retirement, they should maintain the same activities and relationships post-retirement as they did pre-retirement in order to preserve existing internal and external structures. Older people are thought to adopt strategies to maintain this continuity and stay connected to their past experiences (Atchley, 1971). A study of the concepts that middle-aged working men and women use to understand their work and family roles supports the idea that continuity in social roles outside the work environment may mitigate the negative effects of retirement on well-being (Reitzes \& Mutran, 2002). Similarly, a study carried out in Hong Kong found that, after retiring, people can maintain or improve their well-being by spending time with families, developing new interests, learning new things, or volunteering (Wu et al, 2005).

A concept related to social participation, Psychological Sense of Community (PSOC), was identified as beneficial to the development of identity, and the building of resilience and well-being in everyday life in Australia (Pretty et al, 2006). Sarason identified a decline in the feeling of PSOC in society, with corresponding increases in loneliness, isolation, and alienation (Sarason, 1974). A development of the concept of PSOC states that sense of community is a perception consisting of four elements: community membership, influence within the community, shared emotional connection, and meeting personal needs through a community (McMillan \& Chavis, 1986). People who sustain a higher level of community connectedness, and thus PSOC, through the retirement transition may therefore be expected to also sustain higher levels of mental health and well-being.

We propose a model of community continuity for successful retirement. We hold that people derive health and well-being from the communities to which they are connected. More important than maintaining the same activities through life is maintaining a connection to important groups or communities of people.

We therefore hypothesize that people who have stronger community connections after they have retired will demonstrate higher levels of health and well-being than those with weaker community connections. We do not propose that such a connection will exist for those in full-time, paid employment, for whom the workplace may provide social connectedness and a sense of community.

This study will also explore whether some components of a sense of community are more important to health and well-being than others. 
Successful Transition to Retirement 6

\section{Method}

Participants

A total of 650 participants were recruited via a research company, which selected respondents based on the criterion that respondents had to be over the age of 45 . In addition, the sample was required to reflect an approximately equal gender distribution, and consist of approximately equal numbers of retirees and non-retirees. The sample for this study was drawn from their online panel membership of more than 400,000 Australians.

The sample consisted of 360 men (Mage=61.1) and 290 women (Mage=58.4). A total of 228 participants were in paid employment, and of these $27 \%$ were in part time or casual employment, $58 \%$ were in full time employment, and $15 \%$ were self employed. When asked what age they would like to retire, $74 \%$ replied 'over the age of 60 '. Of the 422 participants who were not working, $18.7 \%$ were unemployed, slightly over $76 \%$ were retired and receiving either a pension or superannuation payment, and the remainder were students or carers.

In terms of lifestyle demographics, $67 \%$ of participants were married or with a partner, and $59 \%$ had a trade or university qualification. In terms of health, $37 \%$ reported no ill health while $17 \%$ indicated that their lifestyle was hampered by 'moderate' or 'a lot' of ill health.

\section{Materials}

The Sense of Community Index version $2(\mathrm{SCl}-2)$ is a 24 item, Likert-type scale that provides a measure of sense of community and its four components of membership, influence, meeting needs, and shared emotional connection (Chavis et al, 2008). The measure of sense of community has a coefficient alpha of .94. The four subscales have coefficient alpha scores of .79 to .86. In the present study, the Cronbach alpha coefficient for membership was .79, for influence was .79, for meeting needs was .84, and for shared emotional connection was 85 .

This scale requires identifying a community referent before the participant completes the scale. One of the demographic questions used in this study asked participants to identify a community or group that they mainly connected with outside their home and family. This community or group was the community referent for completing the $\mathrm{SCl}-2$. The demographic question also provided the option of connecting to no community or group. Interestingly, 253 participants (39\%) indicated they were not involved in any community or group, and did not connect with any group outside of family and home. While speculative, this may be an artifact of the sample demographic given 436 (67\%) of the participants were married while 222 (35\%) were working full time suggesting that time and familial responsibilities may reduce the need and opportunity for outside connections.

Mental health was assessed using the Depression, Anxiety, and Stress Scale (DASS) (Lovibond \& Lovibond, 1995). The DASS-21 is a set of three, 7-item, self-report scales designed to measure the negative emotional states of depression, anxiety, and stress. The Depression scale assesses dysphoria, hopelessness, devaluation of life, selfdeprecation, lack of interest/involvement, anhedonia, and inertia while the Anxiety scale assesses autonomic arousal, skeletal muscle effects, situational anxiety, and subjective experience of anxious affect. The Stress scale assesses difficulty relaxing, nervous arousal, and being easily upset/agitated, irritable/over-reactive, and impatient. Participants were asked to rate each item using 4-point severity/frequency scales to indicate the extent to which they have experienced each state over the past week. Scores for Depression, Anxiety, and Stress are calculated by summing the scores for the relevant items. The internal consistency of the depression, anxiety, and stress scales were found to be .94, .87, and .91 respectively for the DASS-21 (Antony et al, 1998). Similar reliabilities were evident in the current study with Cronbach alphas of $.93, .81$ and .88 respectively.

The Satisfaction With Life Scale (SWLS) is a measure of life satisfaction (Diener et al, 1985). The self-report scale consists of 5 items assessing the more general construct of subjective well-being. As such, SWLS is a global measure of life satisfaction. Participants indicated their degree of agreement or disagreement on a 7-point Likerttype scale. This scale has good reliability, evidencing a Cronbach alpha of .92 in the current study.

Participants' level of happiness was assessed using the single item, 'Overall, how happy are you?' Agreement or disagreement was indicated on a 4-point Likert-type scale. 


\section{P. Forster \& M. Morris}

\section{Procedure}

Ethical approval was obtained prior to employing a commercial research company to recruit participants for the study. The questionnaire was uploaded to Qualtrics and deployed via the research company. Data were downloaded into SPSS once the sampling was complete.

\section{Results}

A total of 650 participants were recruited and completed the survey. However, as previously noted, nearly $39 \%$ $(\mathrm{N}=253)$ indicated they had no connection outside of family and home, and were thus not required to complete the Sense of Community Questionnaire, thereby reducing the available $\mathrm{N}$ in subsequent analyses.

Preliminary inspection of the data indicated that the participants showed relatively high levels of psychological well-being as evidenced by the average Stress ( $M=11.27, S D=4.08)$, Depression $(M=9.21, S D=3.12)$, and Anxiety $(M=10.78, S D=4.66)$ scores, which were significantly below the midpoint of the scales $(p<.001$ in all cases) whilst Satisfaction with Life (SWL) was, on average, significantly above the midpoint $(t(645)=9.63, p=.00)$. As such, the sample did not evidence psychopathology.

Table 1. Maximum and minimum scores, means, and standard deviations for Psychological Well-being, Sense of Community and Happiness measures.

\begin{tabular}{|l|r|r|r|r|r|}
\hline & N & \multicolumn{1}{|l|}{ Min. } & \multicolumn{1}{l|}{ Max. } & Mean & \multicolumn{1}{l|}{ SD } \\
\hline Stress & 646 & 7 & 28 & 11.27 & 4.08 \\
\hline Satisfaction with Life & 646 & 5 & 35 & 22.84 & 7.49 \\
\hline Depression & 646 & 7 & 28 & 9.21 & 3.12 \\
\hline Anxiety & 646 & 7 & 28 & 10.78 & 4.66 \\
\hline Sense of Community & 393 & 9 & 72 & 37.38 & 12.48 \\
\hline Happiness & 649 & 1 & 4 & 3.19 & .74 \\
\hline
\end{tabular}

Note: 253 participants were not involved with any community or group outside of home and family.

Table 2. Means (and standard deviations) for community connectedness (yes/no) and retirement status (yes/no) on psychological well-being constructs

\begin{tabular}{|l|r|r|r|r|r|}
\hline & \multicolumn{1}{|c|}{ SWL } & Anxiety & \multicolumn{1}{c|}{ Depression } & \multicolumn{1}{c|}{ Stress } & Happiness \\
\hline Connected & & & & & \\
\hline Yes & $24.05(7.1)$ & $10.27(4.1)$ & $8.9(2.7)$ & $11.23(3.8)$ & $3.27(.73)$ \\
\hline No & $21.0(7.8)$ & $11.55(5.4)$ & $9.6(3.7)$ & $11.31(4.5)$ & $3.09(.76)$ \\
\hline Retired & & & & & \\
\hline Yes & $22.7(6.8)$ & $10.21(3.9)$ & $8.71(2.3)$ & $11.20(3.6)$ & $3.11(.73)$ \\
\hline No & $22.9(7.8)$ & $11.06(5.0)$ & $9.4(3.5)$ & $11.3(4.3)$ & $3.24(.75)$ \\
\hline
\end{tabular}

These data suggest that participants who indicated they had connections outside of their family and home evidenced higher levels of psychological well-being than those who did not indicate outside connections. Similarly, participants who were retired evidenced lower levels of psychological distress but were no more satisfied with their lives than those who had not retired. This suggests that psychological well-being may be more associated with connectedness than employment status.

Sense of Community and Psychological Well-Being

Sense of community for those who had retired $(N=264)$, was negatively associated with anxiety, $r=-.20, p<.01$ and positively associated with SWL, $r=.22, p<.01$. For these participants, each subscale of the SCl-2 was negatively associated with anxiety (meeting needs, $r=-.19, p<.01$; membership, $r=-.19, p<.01$; influence, $r=-$ $.19, p<.01$, and shared emotional connection, $r=-.15, p<.05$ ), and positively associated with SWL (meeting needs, $r=.22, p<.01$; membership, $r=.19, p<.01$; influence, $r=.19, p<.01$, and shared emotional connection, $r=$ $.18, p<.01)$. There were no significant associations between sense of community and depression or stress. 
Table 3. The relationships between sense of community and its sub-factors, and psychological wellbeing factors, anxiety and SWL, for retirees $(\mathrm{N}=264)$

\begin{tabular}{|l|r|r|r|r|r|}
\hline & $\begin{array}{c}\text { Sense of } \\
\text { community }\end{array}$ & $\begin{array}{c}\text { Meeting } \\
\text { needs }\end{array}$ & Membership & Influence & Emotional \\
\hline Anxiety Pearson's r & -.20 & -.19 & -.19 & -.19 & .01 \\
Sig. (2-tailed) & .01 & .01 & .01 & .15 \\
\hline TotSWL Pearson's r & .22 & .01 & .19 & .19 & .01 \\
Sig. (2-tailed) & .01 & .01 & .01 & .01 & .01 \\
& & & & & .01 \\
\hline
\end{tabular}

In contrast to the retirees, for participants in full time, paid employment $(\mathrm{N}=149)$ there were no significant associations between sense of community and any measure of psychological well-being. There was, however, a significant positive correlation between SWL and SOC, $r=.22, p<.01$.

A two-way, between-groups analysis of variance (ANOVA) was carried out to explore the effect of retirement status and community connection on overall Happiness. Participants were divided into those who were in paid employment $(\mathrm{N}=283)$ or retired $(\mathrm{N}=363)$, and those who were connected to a community group $(\mathrm{N}=389)$ or not $(\mathrm{N}=257)$. There was a significant main effect of retirement status, $F(1,555)=5.68, p=.02$ and a significant interaction between the groups, $F(1,555)=4.33, p=.04$, with community connected retirees having the highest level of happiness while those in full time employment who were members of community groups had the lowest level.

Table 4. The effect of employment status and sense of community on overall happiness Tests of between-subjects effects

\begin{tabular}{|c|c|c|c|c|c|}
\hline Source & $\begin{array}{c}\text { Type III Sum of } \\
\text { Squares }\end{array}$ & $\mathrm{df}$ & Mean Square & $\mathrm{F}$ & Sig. \\
\hline Corrected Model & $7.90^{\mathrm{a}}$ & 3 & 2.63 & 5.41 & .00 \\
\hline Intercept & 5162.51 & 1 & 5162.51 & 10598.08 & .00 \\
\hline Sense of community & .79 & 1 & .79 & 1.62 & .20 \\
\hline Employment status & 2.77 & 1 & 2.77 & 5.68 & .02 \\
\hline $\begin{array}{l}\text { Sense of community } \\
\text { Employment status }\end{array}$ & 2.11 & 1 & 2.11 & 4.33 & .04 \\
\hline Error & 269.38 & 553 & .49 & & \\
\hline Total & 6049.00 & 557 & & & \\
\hline Corrected Total & 277.28 & 556 & & & \\
\hline
\end{tabular}

${ }^{\mathrm{a}} \mathrm{R}$ Squared $=.029$ (Adjusted R Squared $=.023$ ) 


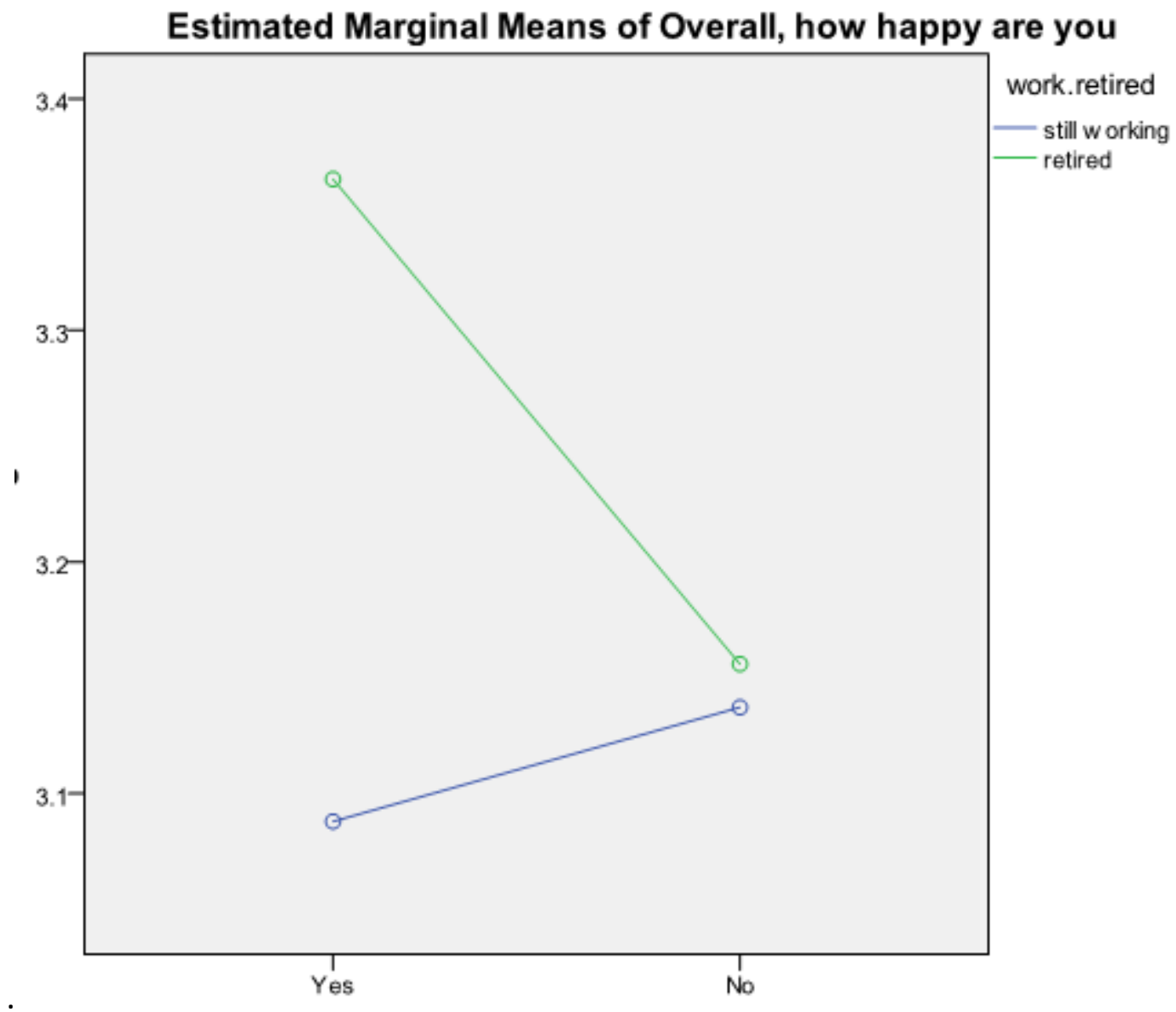

Figure 1. Happiness scores as a function of retirement status (still working or retired) and community connectedness (Yes or No).

To explore individual aspects of well-being, the same analyses were performed on each of the three DASS subscales. In terms of stress, there was no significant main effect of community connection, $F(1,642)=.00, p>.05$, or retirement status, $F(1,642)=.11, p=.74$. There was a significant interaction between the groups, $F(1,642)=$ $5.59, p=.01$, with those in full time employment who were members of other community groups (M=11.47) having a higher level of life stress than those who had retired or who worked and were not connected to a community (Mrange= $10.36-10.58$ ).

In contrast to stress, there was a significant main effect of retirement status, $F(1,642)=11.24, p=.00$, and community connection, $F(1,642)=9.37, p=.00$ on depression. There was a significant interaction between the groups, $F(1,642)=5.81, p=.02$, with those in full time employment who were members of other community groups having the lowest level of depression while those who were retired and not connected to a community group having the highest level. A similar pattern emerged for anxiety as there was a significant main effect of retirement status, $F(1,642)=4.08, p=.04$, and community connection, $F(1,642)=12.24, p=.00$. There was a significant interaction between the groups, $F(1,642)=4.17, p=.04$, with those connected to community groups, independent of their employment status, having the lowest level of anxiety, while those who were retired and not connected to a community group having the highest level.

The sample data were divided into four groups representing the combination of retirement status and community connectedness. An ANOVA indicated a significant difference between the groups with respect to $S W L(F(3,343)$ $=3.04, p=.03$ ). A post hoc Least Square Difference (LSD) test indicated that retirees with high community connectedness $(M=25.58)$ had significantly higher scores on SWL than employed participants independent of their 
community connectedness (Mrange=22.6 - 23.5).

It is possible that general physical health impacts psychological well-being in this older sample population. The sample was divided into those who had no health issues and those who had one or more issues. As expected, without exception, those who had health issues evidenced significantly higher stress $(M=12.12)$, depression $(M=10.0)$, and anxiety scores $(M=11.90)$, and lower life satisfaction $(M=21.07)$ scores $(t(644)=$ range 7.15 to 8.85 , $\mathrm{p}=.01$ ). To further explore the contribution of general health to psychological well-being and connectedness to community, a series of multiple regressions was performed. Physical health was entered at step one, and sense of community scores at step two using well-being, happiness, and SWL as the dependent variables. Physical health was the only significant predictor of well-being $(F(1,387)=42.70, p=.00)$. However, sense of community was a significant predictor of happiness $(F(1,390)=14.82, p=.00)$ and SWL $(F(1,386)=13.05, p=.00)$ after controlling for physical health $(F(1,390)=48.60, p=.00)$. This result was consistent when the retired group and the employed group were analysed separately.

It is also possible that family and friends contributed to level of happiness. To explore this possibility, health status was entered at step one, the number of positive relationships with family and friends was entered at step two, and sense of community at the final step. Interestingly, sense of community remained a significant predictor of happiness $(F(1,387)=7.47, p=.00)$ over and above health and family and friends. This relationship remained when only retirees were used in the analyses (sense of community, $F(1,215)=6.21$ ), $p=01$ ).

To further explore the impact of family and friends on well-being, the sample was divided into four groups on the basis of the number of family members (high, low) and friends (high, low) with whom they had positive relationships. Without exception, when all measures of psychological well-being were employed, significant differences were evident between the groups with the low family/low friends group consistently evidencing the lowest well-being scores $(F(3,645)$ range $=3.26$ to $30.42, p<.05)$.

\section{Discussion}

Our observation of a positive correlation between PSOC and well-being is consistent with the idea that there is a clear connection between community engagement and successful retirement, manifesting as positive mental health, although the design does not allow us to state that this connection is causal. It may also be seen as consistent with the social identity framework, which proposes that, to be satisfied with retirement, people must be actively involved with other retirees, rather than simply define themselves as a member of that group (Michinov et al, 2008). In other words, satisfied retirees enjoy being a member of that group or meeting other retirees. If this correlation was the only finding, however, it could be interpreted as people who are more satisfied with life are more likely to engage with their fellow retirees. The interactions observed in the ANOVAs, in which the greatest satisfaction was observed in community-connected retirees and the least satisfaction in the community-connected employed people, suggest that it is engaging with social groups that adds to the overall satisfaction with life for retired people, whereas it detracts from that of people in employment, for whom it may constitute an excessive demand on resources. Similarly, people who were retired and not connected to a social group were the most anxious and most depressed, whereas those who were employed but not connected to a social group were the least anxious, least depressed, and least stressed.

The latter point is noteworthy. It is usual to see community connectedness as a positive resource: a source of strength on which one can draw. Communities are usually only seen as a source of stress when conflict emerges between community members (Cherniss \& Degan, 2000). Yet the results of this study show that being connected to a community group can be a source of stress. The interaction between retirement status and community group membership reveals this possibility. As indicated above, being connected to a community was a source of health and well-being for those who had retired. However, those in full-time employment were better off if they were not connected to community groups. One possible explanation for this observation is that, those who are in full-time employment and are not connected to other communities are at, or close to, the optimum level of demands for which they have the coping resources. Adding other community involvements may serve to take them beyond that optimum level and into the zone where they feel they lack adequate coping resources, with resulting negative consequences for health and well-being. This point merits further investigation.

The importance of social connections to retirees is further highlighted by our finding that social connections 


\section{P. Forster \& M. Morris}

contribute to well-being, independent of a person's physical health and also of the number of their close family connections. The number of close family and friends also made an independent contribution to overall well-being. And finally, the group with the highest levels of well-being was that in which the members were both retired and had a high sense of community. So an implication of the present study is that retirement preparation and counselling should include advice about social connectedness and developing positive relationships, particularly for those soon-to-be retirees who are not already connected to family, friends, or supportive community groups.

Future research could focus on part-time workers, as community connectedness may have different effects on that group than on the retired or on full-time workers. The reason for the reduced well-being observed among full-time workers who are members of community groups also needs further investigation.

It would also be useful to extend this study over time with a view to examining the effects of community connectedness as people move through the retirement transition.

\section{References}

Shultz, K. S., \& Wang, M. (2011) Psychological perspectives on the changing nature of retirement. American Psychologist, 66: 170-179

Ekerdt, D. J. (2010). Frontiers of research on work and retirement. Journal of Gerontology: Social Sciences, 65B: 6980. doi:10.1093/geronb/gbp109

Australian Bureau of Statistics (2009). Employment arrangements, retirement and superannuation, Australia, April to July 2007 (Reissue) (ABS catalogue number 6361.0). Retrieved from http://www.abs.gov.au/ausstats/abs@.nsf/mf/6361.0

Stokes, G. (1992). On being old: The psychology of later life. London: Falmer Press

Cumming, E., Henry, W. E., \& Damianopoulos. (1961) A formal statement of disengagement theory. In E. Cumming \& W. E. Henry (Eds), Growing old: The process of disengagement. New York: Basic Books

Kloep, M., \& Hendry, L. B. (2006) Entry or exit? Transitions into retirement. Journal of Occupational and Organizational Psychology, 79: 569-593

Bowling, A., Gabriel, Z., Banister, D., \& Sutton, S. (2004) Adding quality to quantity: Older people's views on their quality of life and its enhancement. ESRC Growing Older Programme, Sheffield

Brown, G. W., \& Harris, T. O. (1978) Social origins of depression: A study of psychiatric disorder in women. London: Tavistock

Monroe, S. M., Imhoff, D. F., Wise, B. D., \& Harris, J. E. (1983) Prediction of psychological symptoms under high-risk psychosocial circumstances: life events, social support, and symptom specificity. Journal of Abnormal Psychology, 92: 338-350

Erikson, E. H. (1959) Identity and the life cycle: Selected papers. Psychological Issues, 1: 1-171

Ebersole, P., Touhy, T., Hess, P. C., Jett, K., \& Luggen, A. S. (2007) Toward healthy aging: Human needs and nursing responses ( $7^{\text {th }}$ ed.) St Louis: Mosby

De Leo, D., Hickey, P. A., Neulinger, K., \& Cantor, C. H. (2001) Ageing and suicide. Commonwealth Department of Health and Aged Care, Canberra

Atchley R. C. (1971) Retirement and leisure participation: Continuity or crisis? The Gerontologist, 11(1): 13-17.

Reitzes, D. C., \& Mutran, E. J. (2002) Self-concept as the organization of roles: Importance, centrality, and balance. Sociological Quarterly, 43: 647-667

Wu, A. S., Tang, C. S., \& Yan, E. C. (2005) Post-retirement voluntary work and psychological functioning among older Chinese in Hong Kong. Journal of Cross-Cultural Gerontology, 20: 27-45

Pretty, G., Bishop, B., Fisher, A., \& Sonn, C. (2006) Psychological sense of community and its relevance to wellbeing and everyday life in Australia. Retrieved http://www.groups.psychology.org.au/Assets/Files/Community-Updated-Sept061.pdf

Sarason, S. B., (1974) The psychological sense of community: Prospects for a community psychology. San Francisco: Jossey-Bass

McMillan, D. W., \& Chavis, D. M. (1986) Sense of community: A definition and theory. Journal of Community Psychology, 14(1): 6-23

Chavis, D. M., Lee, K. S., \& Acosta J. D. (2008) The Sense of Community (SCI) Revised: The Reliability and Validity of 
the SCl-2. Paper presented at the 2nd International Community Psychology Conference, Lisboa, Portugal

Lovibond, P. F., \& Lovibond, S. H. (1995) Manual for the Depression Anxiety Stress Scales. Sydney, Australia: Psychology Foundation of Australia

Antony, M. M., Bieling, P. J., Cox, B. J., Enns, M. W., \& Swinson, R. P. (1998) Psychometric properties of the 42 -item and 21-item versions of the Depression Anxiety Stress Scales in clinical groups and a community sample. Psychological Assessment, 10(2): 176-181

Diener, E., Emmons, R. A., Larsen, R. J., \& Griffin, S. (1985) The satisfaction with life scale. Journal of Personality Assessment, 49: 71-75

Michinov, E., Fouquereau, E., \& Fernandez, A. (2008) Retirees' social identity and satisfaction with retirement. International Journal of Aging and Human Development, 66(3): 175-194

Cherniss, C., \& Deegan, G. (2000) The creation of alternative settings. In J. Rappaport \& E. Seidman (Eds.), Handbook of community psychology (pp. 359-377). New York: Kluwer Academic 